\title{
CASE OF EXSTROPHY OF BLADDER AND SPLIT PELVIS COMPLICATING LABOUR.
}

\author{
By JAMES ADAM, M.A., M.D.
}

I HAVE been asked to publish a note of this case of exstrophy of bladder and split pelvis complicating labour. The interest of it seems to me to be mainly clinical, though, of course, it is of importance from the developmental standpoint. Ample reference to this subject will be found in Dr. Berry Hart's paper on 'Extroversio Vesicæ and apparent Low Implantation of the Ureter End.'* Klein, $\dagger$ whose paper is there mentioned, gives a table of seven labours with this anomaly. Reference to the subject is also made by Champneys. $\ddagger$

The patient, as I first saw her in November, Igoo, was a wellnourished woman, aged twenty-two, and about five months pregnant. In earlier years she had been told by a doctor that the extroversion might get all right when she was twenty-one. She seems to have believed and acted on this opinion; at any rate, she got married at that age.

Examination of the abdomen showed the following three structures from above downwards :

I. An umbilical area of about 3 inches diameter, covered by thin, parchment-like cuticle, which hardly seemed strong enough to retain the protruding intestine; yet the hernia did not enlarge.

2. A vesical area immediately adjoining the umbilical area above, of about the same diameter, and extending below to the tissue which replaced the pubic symphysis. This area-really a small portion of the posterior wall of the bladder-projected about $I$ inch above the general surface, and shaded off at its margin into the surrounding skin, but at its inferior and most prominent part presented a raw, excessively tender, mucous surface, on which the ureters opened about I inch apart, and from which tiny jets of urine occasionally spurted over the parts below (there was not a continuous passive trickling). Gentle pressure just above the ureteral orifices would sometimes cause a spurt of urine, so that evidently there was a small ampulla of each ureter just above its orifice.

\footnotetext{
* Journ. Anat. and Physiol., vol. xxxv., p. 37.

+ Arch. für Gynäk., Bd. xliii., 1938.

\$ St. Barth. Hosp. Rep., 1877 , vol. xiii, p. $8 \mathrm{I}$.
} 


\section{$37^{8}$ Journal of Obstetrics and Gynæcology}

3. Below the vesical area and separating it from the vaginal orifice was a very firm fibrous band, uniting the gap between the pubic bones. This gap measured $3 \frac{3}{8}$ inches. The lower end of the recti muscles seemed to be attached to the bones, and not to the fascia, and converged upward to the middle line above the umbilical area.

Separating the lower part of the median area, described above, from the thighs were the labia majora. These were large and diverged upwards. Just inside them, inferiorly, were the enlarged œdematous nymphæ. The left was specially odematous and pendulous, almost hanging between the thighs.

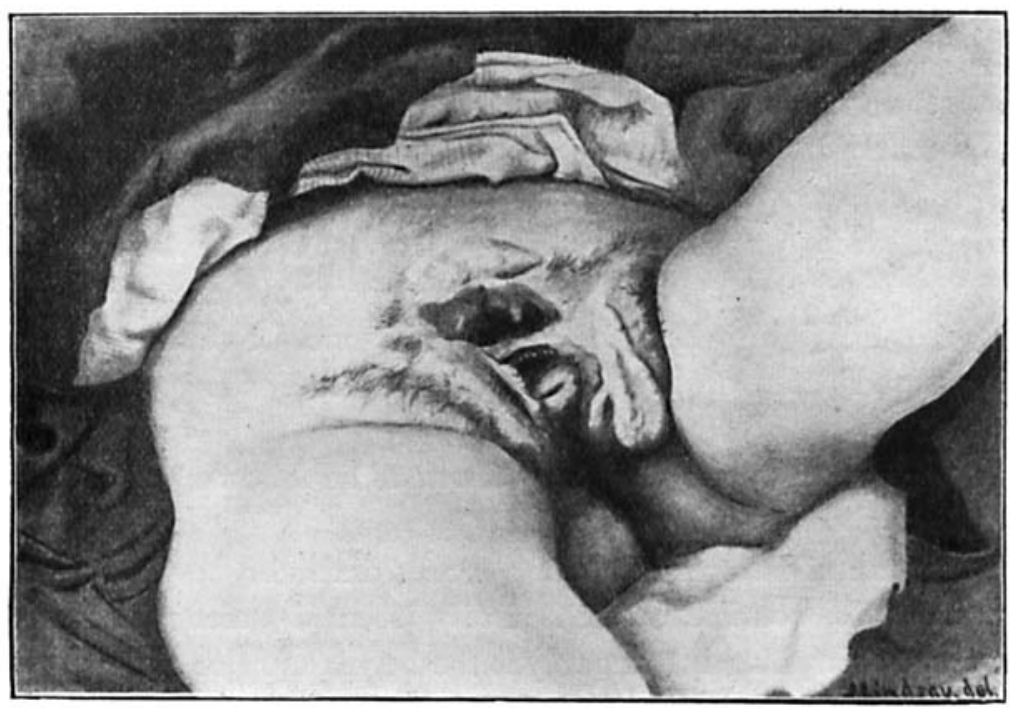

Fici. I. Exstrophy of Bladder and Split Pelvis.

The vaginal orifice was surrounded by a soft fringe of mucous membrane, and with difficulty admitted two fingers. The os uteri was within an inch of the orifice, the anterior fornix being easily reached in front of the os, but the posterior fornix lay much deeper, say $2 \frac{1}{2}$ inches. This greater depth seemed due to the perineum being longer and thicker than normal, for otherwise the vagina was decidedly short. I could make out no trace of the clitoris.

The patient during the day wore a rubber urinal; at night she lay on pads.

Previous to conception, menstruation had always been easy and regular every four weeks.

For the greater part of the last three months of pregnancy 
she had to lie in bed owing to œedema of the labia minora, and threatened prolapse of the uterus.

I was called to her on March $3 \mathrm{r}$, and found decided uterine contraction, but the cervical canal still quite distinct. Temperature was $103^{\circ} 5^{\circ}$, and had evidently been up for some days previous, as malaise, loss of appetite, and a feeling of feverishness had existed for about a week. Also she had had three hours of uterine pains on the previous day. I gave a morphia suppository, the pains ceased, and the patient slept. Next morning, April I, she felt fairly well, and the temperature was $100^{\circ} 2^{\circ}$, but at 4 p.m. and 9 p.m. was $104^{\circ}$, notwithstanding quinine and salol. Labour began at Ir p.m., and at 3 p.m., April 2, I found the membranes tense and protruding at the vaginal orifice. The long, tough perineum, and possibly the

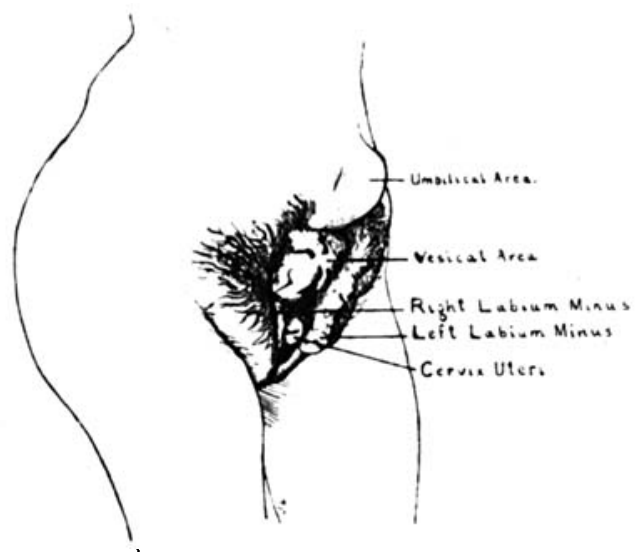

Fig. 2.-Exstrophy of Bladder and Spilt Pelvis. Semi-profile VIEW IN OUTLINE.

pubic gap, caused the head to pass unusually well forward, and a healthy female child, weighing probably 6 pounds, was soon born. The anterior part of the perineum, and also the soft fringe round the vaginal orifice, were torn. The membranes were adherent at the fundus: I had twice to insert my hand to remove them. For this reason, and considering that the bruised, lacerated parts were constantly bathed in urine, that the patient had a high temperature, and that her mother and only sister died in childbed, I gave an intra-uterine douche (weak carbolic in boiled water), stitched the perineum-in order if possible to cover the os-dusted with aristol, and applied a bichloride dressing. At II a.m. temperature was $97^{\circ} 2^{\circ}$; at 8 p.m., Ior' 5 .

The following day (second of puerperium) the temperature at noon was $103^{\circ} 3^{\circ}$; the parts round the vaginal orifice black and 
sloughy, the cervix presenting there and its superficial parts also sloughing; abdomen distended. Vaginal douche (weak bichloride); boric wool substituted for the bichloride dressing; salol and calomel internally. Third day of puerperium : Temperature at II a.m., $95^{\circ} 5^{\circ}$; at 9 p.m., $99^{\circ} 5^{\circ}$. Bowels moved twice. Os and cervix projecting about 2 inches beyond vaginal orifice, and covered with dark superficial slough.

After this the temperature kept subnormal, but vaginal douching was continued till the sloughs separated, about the sixth and seventh days. For a time the patient's chances seemed small-high temperature, abdomen distended, the thin, parchment-like umbilical area ballooned out with intestine, the margin of the vaginal orifice sloughing, and, together with the superficially sloughing and exposed cervix, constantly bathed in urine. To my great surprise, the perineal stitches held, and the wound healed in greater part. I failed to make out the exact cause of the pyrexia, which was even more marked before than after labour. Possibly constipation, which was troublesome, had something to do with it. For this reason salol, calomel, and saline purgatives were given.

It is to be noted that whereas Klein says that in most of the seven labours complicated by exstrophy of the bladder, as tabulated by him,* the perineum gave trouble, and required incision, there was no need for operative interference in this case, although the perineum was long and tough. The somewhat small size of the child may account for this.

As involution proceeded the cervix gradually receded till it came to lie just at the vaginal orifice. Prolapse, of course, now occurs with the erect posture; but the womb is easily kept up by a rubber cup-and-stem pessary, which the patient wears in addition to her rubber urinal. She was seen by Dr. R. H. Parry with a view to operation for the extroversion; but this she in the meantime declines.

A photograph was taken on the fifth day, from which, and from an examination of the patient at much trouble to himself, my friend, Dr. John Lindsay, of Glasgow, has made the drawings which illustrate this communication.

* At least three of the children were dead. 